\title{
Communication-Less Frequency Support from Offshore Wind Farms Connected to HVdc via Diode Rectifiers
}

Saborío-Romano, Oscar; Bidadfar, Ali; Sakamuri, Jayachandra Naidu; Zeni, Lorenzo; Goksu, Ömer; Cutululis, Nicolaos Antonio

Published in:

IEEE Transactions on Sustainable Energy

Link to article, DOI:

10.1109/TSTE.2020.3004630

Publication date:

2021

Document Version

Peer reviewed version

Link back to DTU Orbit

Citation (APA):

Saborío-Romano, O., Bidadfar, A., Sakamuri, J. N., Zeni, L., Goksu, Ö., \& Cutululis, N. A. (2021).

Communication-Less Frequency Support from Offshore Wind Farms Connected to HVdc via Diode Rectifiers.

IEEE Transactions on Sustainable Energy, 12(1), 441-450. https://doi.org/10.1109/TSTE.2020.3004630

\section{General rights}

Copyright and moral rights for the publications made accessible in the public portal are retained by the authors and/or other copyright owners and it is a condition of accessing publications that users recognise and abide by the legal requirements associated with these rights.

- Users may download and print one copy of any publication from the public portal for the purpose of private study or research.

- You may not further distribute the material or use it for any profit-making activity or commercial gain

- You may freely distribute the URL identifying the publication in the public portal 


\title{
Communication-Less Frequency Support from Offshore Wind Farms Connected to HVdc via Diode Rectifiers
}

\author{
Oscar Saborío-Romano ${ }^{(\mathbb{D}}$, Student Member, IEEE, Ali Bidadfar ${ }^{(\mathbb{D}}$, Member, IEEE, Jayachandra N. Sakamuri ${ }^{(\mathbb{D})}$, \\ Lorenzo Zeni, Member, IEEE, Ömer Göksu ${ }^{\mathbb{D}}$, and Nicolaos A. Cutululis ${ }^{\mathbb{D}}$, Senior Member, IEEE
}

\begin{abstract}
Before diode rectifier (DR) technology for connecting offshore wind farms (OWFs) to HVdc is deployed, indepth studies are needed to assess the actual capabilities of DRconnected OWFs to contribute to the secure operation of the networks linked to them. This study assesses the capability of such an OWF to provide communication-less frequency support (CLFS) to an onshore ac network. It is shown that the HVdc link's offshore terminal direct voltage can be estimated from measurements at the OWF's point of connection with the DR platform. Two different methods are proposed for implementing CLFS in the OWF active power controls. In Method 1, the estimated offshore terminal direct voltage is used for estimating the onshore frequency deviation. In Method 2, the actual offshore terminal direct voltage measurement is used instead. Unique features of the provision of CLFS from OWFs connected to HVdc via DRs are highlighted, and the dynamic and static performance of the CLFS control scheme is compared to that of the communication-based frequency support scheme. To assess the impact of parameter estimation errors on the provision of CLFS, a parametric sensitivity study is presented as well, and recommendations are given to increase accuracy.
\end{abstract}

Index Terms-Diode-rectifier-based HVdc transmission, frequency support, grid-forming wind turbine control, offshore wind energy integration, primary frequency response

\section{INTRODUCTION}

$\mathbf{E}$ XPLOITING Europe's offshore wind resources further requires the development of electrical infrastructure connecting offshore wind farms (OWFs) and onshore networks. To date, only a few OWFs are connected via HVdc, while the majority export their production through HVac. However, as the distance from shore and OWF size increase and the associated costs decrease, the amount of HVdc-connected OWFs is widely expected to increase.

Since its introduction in 1997, HVdc transmission technology using voltage source (forced-/self-commutated) converters (VSCs), based on insulated-gate bipolar transistors, has developed significantly. VSC-based HVdc transmission (VSCHVdc) offers advantages such as independent control of active

This work has received funding from the European Union's Horizon 2020 research and innovation programme under grant agreement No 691714.

O. Saborío-Romano, A. Bidadfar, Ö. Göksu and N. A. Cutululis are with the Department of Wind Energy, Technical University of Denmark, Frederiksborgvej 399, 4000 Roskilde, Denmark (e-mail: osro@dtu.dk; abid@dtu.dk; omeg@dtu.dk; niac@dtu.dk).

L. Zeni is with Ørsted Offshore, Nesa Allé 1, 2820 Gentofte, Denmark (e-mail: lorze@orsted.dk).

J. N. Sakamuri is with Vattenfall, Jupitervej 6, 6000 Kolding, Denmark (e-mail: jayachandranaidu.sakamuri@ vattenfall.com). and reactive power, smaller footprints, fast reversibility of active power flow and the (grid-forming) capability to form ac networks, i.e. to control their ac-side voltage magnitude and frequency. Owing to such advantages, the use of VSCbased offshore HVdc terminals has enabled the development of HVdc-connected OWFs with the prevailing grid-following approach to controlling wind turbines (WTs), in which WTs rely on other (grid-forming) units (e.g. VSC-based offshore HVdc terminals) forming their ac network.

Recently suggested as a feasible alternative for connecting OWFs to HVdc, (uncontrolled, line-commutated) diode rectifiers (DRs) have prompted increasing interest from both academia and industry [1]-[6]. DR-based offshore HVdc terminals offer advantages such as higher reliability, lower costs, higher efficiency and smaller footprints [3], [5]. Since diodes are passive devices, however, such offshore HVdc terminals are inherently devoid of the grid-forming capability of VSCs. WTs have therefore been suggested as feasible candidates to take over such responsibility. This entails fundamentally different WT and WF controls, changing their control approach from that of grid-following units to that of grid-forming units [1], [4].

HVdc-connected OWFs and the corresponding HVdc power transmission networks can be required to contribute to the secure operation of the onshore ac networks connected to them by means of e.g. fault ride-through, black start and restoration, rotor angle stability-related control, reactive power/alternating voltage control and active power/frequency control. The capabilities of VSC-HVdc-connected OWFs and the corresponding HVdc power transmission networks to provide such services are well established. In-depth studies are, however, needed to assess the actual capabilities of DR-connected OWFs to contribute in the provision of such services before such technology is deployed [7].

A control strategy for the provision of frequency support (FS) from HVdc-connected WFs was first developed in [8], based on the long-distance communication of the remote ac network's frequency to the WF-side HVdc terminal, hereinafter referred to as communication-based frequency support (CBFS). To avoid the need for long-distance communication, communication-less schemes have been subsequently proposed for the provision of FS, hereinafter referred to as communication-less frequency support (CLFS), from VSCHVdc-connected OWFs [9], [10]. The term communicationless means, in this context, without long-distance communi- 
cation, i.e. all quantities needed by each controller can be measured locally. For an OWF, locally means at its point of connection, which may be extended for DR-connected OWFs to include the DR platform.

The capability of DR-connected OWFs to provide CBFS to onshore ac networks by means of plant-level controls similar to those devised for VSC-connected OWFs has been investigated in [11], using models and grid-forming WT frontend converter (FEC) controls based on those in [1]-[3], and an aggregated representation of the $\mathrm{OWF}$ as a single equivalent WT. The analysis has been extended in [12], using more detailed component models based on those in [13], a semiaggregated representation of the OWF and improved gridforming WT FEC controls based on those in [6].

To date, CLFS from DR-connected OWFs has only been studied in [14], where supplementary WT controls have been proposed to detect the onshore frequency event via the corresponding change in the magnitude of the voltage in the offshore ac network (clamped to the HVdc network voltage) and change the WT active power output by manipulating the pitch angle, once the fluctuation in voltage magnitude surpasses a certain threshold value. The performance of such controls has been illustrated by simulation results corresponding to two operating points very close to each other, not considering the accuracy with regards to the expected changes in WF active power output in response to the changes in the frequency of the onshore ac network. However, since the voltage drop over the DRs varies with the operating point, an accurate provision of CLFS with such controls over the whole operating range of the OWF will inevitably require that:

- such WTs receive information about the operating point (e.g. WF active power or current output) that is not available from measurements local to the WTs, and that

- some parameters of the proposed supplementary WT controls (e.g. voltage magnitude threshold, droop) vary with the operating point.

The main contribution of this work, extending the assessment conducted in [12], is to include the capability of the DRconnected OWF to provide CLFS to an onshore ac network by means of plant-level controls similar to those devised for VSCconnected OWFs. It is shown that the HVdc link's offshore terminal direct voltage can be estimated from measurements at the OWF's point of connection with the DR platform and offline estimation of parameters corresponding to the DR platform. Furthermore, it is shown that the onshore frequency deviation can in turn be estimated from the offshore terminal direct voltage estimation and the coordinated selection of the corresponding droops in the onshore terminal and OWF active power controls.

Two different methods are proposed for implementing CLFS in the WF active power controls. In Method 1, the estimated offshore terminal direct voltage is used for estimating the onshore frequency deviation. In Method 2, the actual offshore terminal direct voltage measurement is used instead.

Through the proposed controls, the OWF modifies its active power output according to the estimation of the onshore frequency deviation. Focus is given to primary frequency response (PFR), based on an active-power-frequency droop, with reserves from curtailed operation considered as the source of additional active power during onshore underfrequency events [13]. Unique features of the provision of CLFS from OWFs connected to HVdc via DRs are highlighted, and the dynamic and static performance of the CLFS control scheme is compared to that of the CBFS scheme. To assess the impact of parameter estimation errors on the provision of CLFS, a parametric sensitivity study is performed as well, and recommendations are given to increase the accuracy in the estimation of such parameters.

The rest of the paper is organised as follows. In Section II, the studied system is detailed and the main control algorithms are described. In Section III, the considered cases are described, and corresponding simulation results are presented and discussed. Finally, concluding remarks are made in Section IV.

\section{Modelling And CONTROL}

Fig. 1 shows the studied system. The system is based on that described in [7], [13] and consists of one of three $400 \mathrm{MW}$ OWFs connected to an onshore ac network by means of a $200 \mathrm{~km}$ long $\pm 320 \mathrm{kV}$ monopolar HVdc link and corresponding onshore $\mathrm{HVdc}$ terminal, operating at a third of the rated voltage (i.e. the nominal voltage is approximately $213 \mathrm{kV}$, and the nominal power is $400 \mathrm{MW}$ ). Balanced/symmetric operation is assumed. The system is modelled in PSCAD. System parameters are given in Table I.

The onshore ac network is represented by a lumped threephase resistive load and a lumped three-phase synchronous machine (SM) with its electrohydraulic governor and hydraulic turbine (with a non-elastic water column and no surge tank), using the corresponding models from the PSCAD Master Library. The share of wind power generation at the connection point is $50 \%$, i.e. the $\mathrm{WF}$ is rated at $400 \mathrm{MW}$, for a total installed capacity of $800 \mathrm{MW}$. The offshore HVdc terminal: one of three diode rectifier platforms (one per OWF), consists of two (uncontrolled, line-commutated) diode-based 12-pulse rectifiers (DRs) connected in series on their dc side, with corresponding reactive power shunt compensation and filter bank on their ac side.

The OWF has 50 grid-forming type-4 (full-converter) $8 \mathrm{MW}$ WTs, laid out in 6 strings. The first string, comprised of WTs 1-9 is represented in detail. The other 5 strings, consisting of WTs 10-50, are aggregated into an equivalent $328 \mathrm{MW}$ WT and corresponding cable equivalent $\pi$ circuit using the method proposed in [15].

The represented WT dynamics focus on the WT front-end (grid-/line-side) network. Dynamics in each WT dc link and behind it are not considered, as they are not relevant to the case in question. The corresponding voltage is thus assumed constant, i.e. ideally regulated by the back-end/machine-side converter [7]. Pulse-width modulation (PWM) is assumed to be done in the linear range, switching effects and any delay due to the implementation of the PWM are neglected, and average value models are used to represent all VSCs (including the VSC-based onshore $\mathrm{HVdc}$ terminal). Focus is given to dynamics not faster than the VSC (inner/lower) current control 


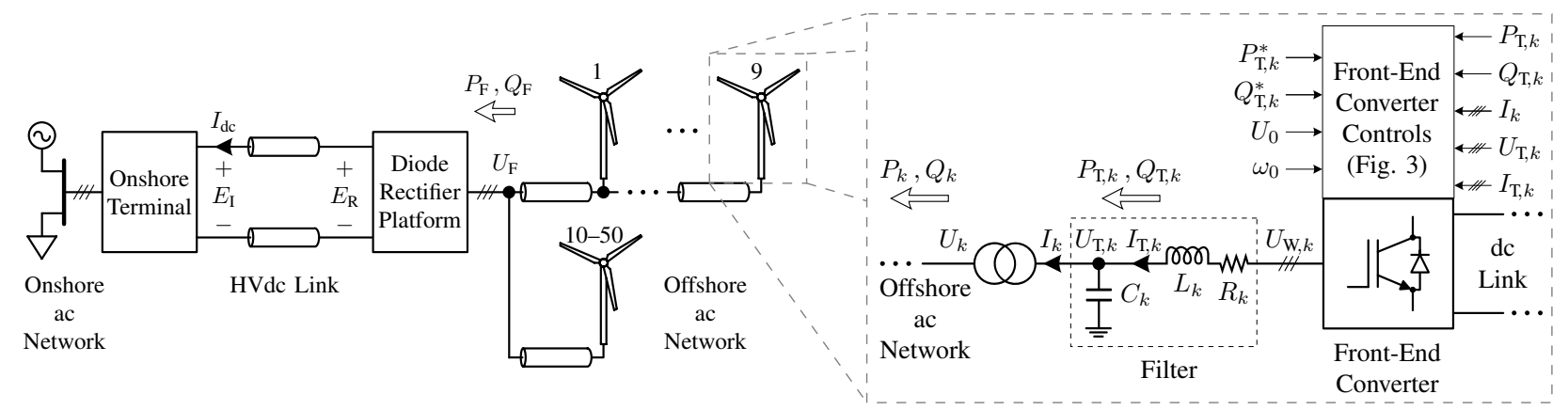

Fig. 1. Studied system

(a) Overview

(b) $k$ th wind turbine front-end (grid-/line-side) network

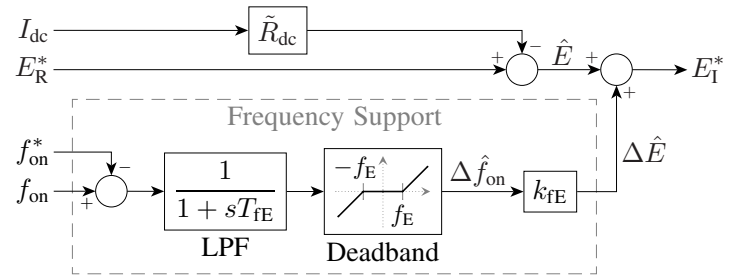

Fig. 2. Onshore terminal outer control loop; parameter values and limits given in Table II

loops, the fastest of which are designed to have a bandwidth of $200 \mathrm{~Hz}$.

\section{A. Onshore Terminal Controls}

The VSC-based onshore HVdc terminal regulates the voltage on its dc terminals, $E_{\mathrm{I}}$, and the reactive power injected into the onshore ac network by means of the controls described in [3]. To study the capability of such an OWF to provide CLFS to an onshore ac network, the onshore terminal controls are extended to include the outer control loop shown in Fig. 2, based on those used in [9], [10], [16] for OWFs connected to HVdc via VSCs. In such loop, the base direct voltage reference, $\hat{E}$, is determined by subtracting the estimated voltage drop on the HVdc link from the offshore terminal direct voltage reference, $E_{\mathrm{R}}^{*}$, which is set to the nominal value. The voltage drop on the HVdc link is calculated using the onshore terminal current measurement, $I_{\mathrm{dc}}$, and the estimated $\mathrm{HVdc}$ link resistance, $\tilde{R}_{\mathrm{dc}}$.

When CLFS is provided, $\hat{E}$ is modified by means of an additional direct voltage reference, $\Delta \hat{E}$, which is determined by a given droop acting on the onshore frequency deviation signal, $\Delta \hat{f}_{\text {on }}$, i.e.

$$
\Delta \hat{E}=k_{\mathrm{fE}} \Delta \hat{f}_{\text {on }} .
$$

$\Delta \hat{f}_{\text {on }}$ is generated by applying a first-order low-pass filter (LPF) and a deadband to the subtraction of the corresponding input signals. Values for the control parameters and limits are given in Table II. Assuming perfect control of the onshore terminal direct voltage, $E_{\mathrm{I}} \approx E_{\mathrm{I}}^{*}$, and perfect estimation of the HVdc link resistance, $\tilde{R}_{\mathrm{dc}} \approx R_{\mathrm{dc}}$,

$$
E_{\mathrm{R}}-E_{\mathrm{R}}^{*}=\Delta E_{\mathrm{R}} \approx \Delta \hat{E}=k_{\mathrm{fE}} \Delta \hat{f}_{\mathrm{on}} .
$$

\section{B. Offshore Terminal Direct Voltage Estimation}

When the (4 diode bridges of the two 12-pulse) DRs are conducting, the relation between alternating and direct voltages on both sides of the DR platform is [17]

$$
E_{\mathrm{R}}=\frac{12 \sqrt{6}}{\pi} N_{\mathrm{T}_{\mathrm{R}}} U_{\mathrm{F}}-\frac{12}{\pi} X_{\mathrm{T}_{\mathrm{R}}} I_{\mathrm{R}, \mathrm{dc}},
$$

where $E_{\mathrm{R}}$ is the average direct voltage, $N_{\mathrm{T}_{\mathrm{R}}}$ is the DR transformer turns ratio, $U_{\mathrm{F}}$ is the rms line-to-neutral alternating voltage, $X_{\mathrm{T}_{\mathrm{R}}}$ is the DR transformer leakage reactance, and $I_{\mathrm{R}, \mathrm{dc}}$ is the direct current flowing out of the DR platform. Moreover, the relation between alternating and direct currents in the DRs (with losses neglected) is [17]

$$
I_{\mathrm{R}, \mathrm{ac}} \cos \phi \approx \frac{2 \sqrt{6}}{\pi} N_{\mathrm{T}_{\mathrm{R}}} I_{\mathrm{R}, \mathrm{dc}}(1+\cos \mu),
$$

where $I_{R, a c}$ is the rms fundamental alternating line current flowing into the DRs, $\phi$ is the angle by which the alternating current associated with $I_{\mathrm{R}, \mathrm{ac}}$ lags the alternating voltage associated with $U_{\mathrm{F}}$, and $\mu$ is the DR commutation overlap angle. Neglecting shunt losses in the DR platform,

$$
I_{\mathrm{R}, \mathrm{ac}} \cos \phi \approx \frac{P_{\mathrm{F}}}{3 U_{\mathrm{F}}},
$$

where $P_{\mathrm{F}}$ is the three-phase active power flowing out of the OWF and into the DR platform. Using (4) and (5), (3) can be rewritten as

$$
\begin{aligned}
\tilde{E}_{\mathrm{R}} & =\frac{12 \sqrt{6}}{\pi} N_{\mathrm{T}_{\mathrm{R}}} U_{\mathrm{F}}-\frac{\sqrt{2 / 3} \tilde{X}_{\mathrm{T}_{\mathrm{R}}}}{N_{\mathrm{T}_{\mathrm{R}}}(1+\cos \tilde{\mu})} \frac{P_{\mathrm{F}}}{U_{\mathrm{F}}} \\
& =k_{\mathrm{UE}} U_{\mathrm{F}}-k_{\mathrm{IE}} \frac{P_{\mathrm{F}}}{U_{\mathrm{F}}},
\end{aligned}
$$

where $\tilde{E}_{\mathrm{R}}$ is the estimated average direct voltage, $\tilde{X}_{\mathrm{T}_{\mathrm{R}}}$ is the estimated DR transformer leakage reactance, and $\tilde{\mu}$ is the estimated DR commutation overlap angle. Equation (6) implies that the offshore terminal direct voltage, $E_{\mathrm{R}}$, can be estimated from measurements local to the OWF, $U_{\mathrm{F}}, P_{\mathrm{F}}$, and knowledge or offline estimation of the parameters corresponding to the DR platform, $N_{\mathrm{T}_{\mathrm{R}}} \tilde{X}_{\mathrm{T}_{\mathrm{R}}}, \tilde{\mu}$. The parameter values used in this work are given in Table III.

If the frequency of the offshore ac network is only allowed to vary within a narrow range around its nominal value (to reduce the size of the filters in the DR platform) [7], the 


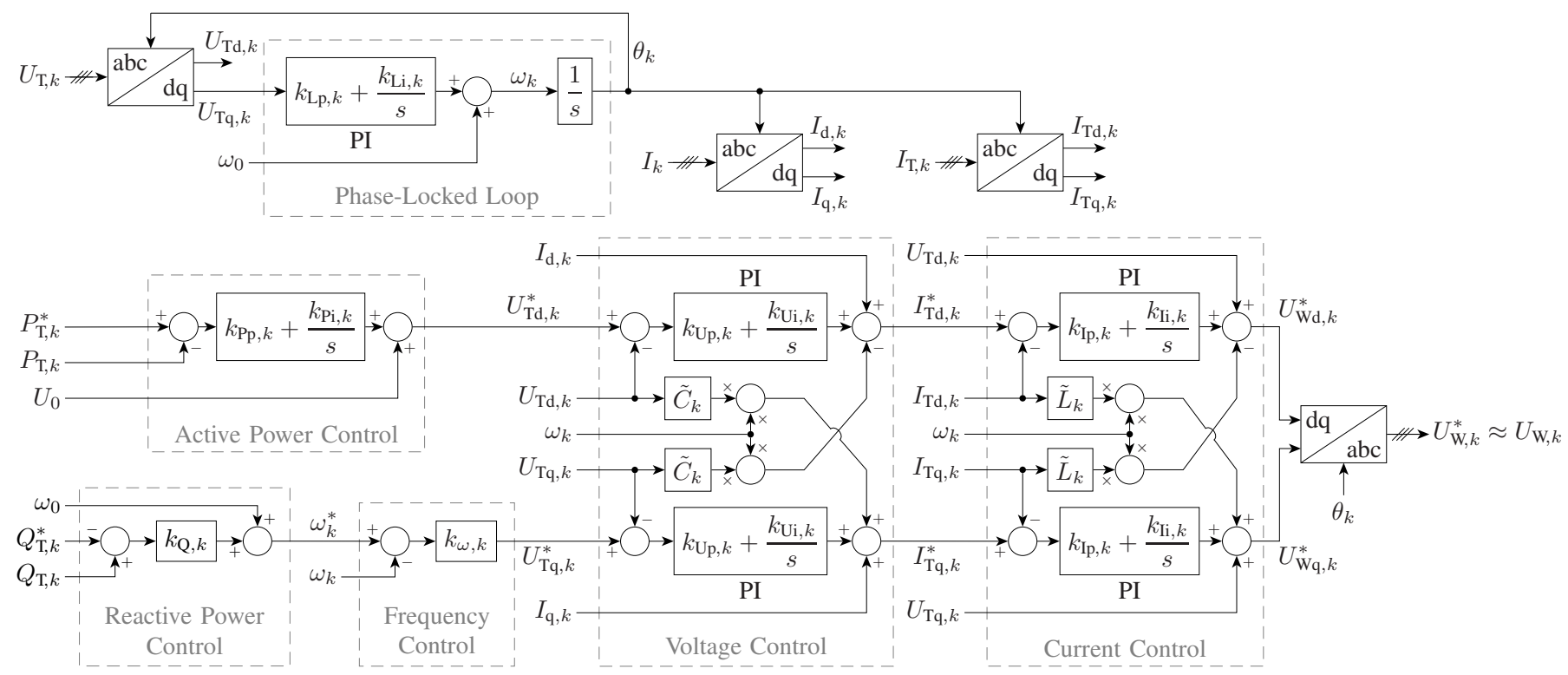

Fig. 3. $k$ th wind turbine front-end (grid-/line-side) converter controls; parameter values and limits given in Table IV

nominal value of the DR transformer leakage reactance, $X_{T_{R}}^{\text {nom }}$, can be used in (6), i.e.

$$
\tilde{X}_{\mathrm{T}_{\mathrm{R}}}=X_{\mathrm{T}_{\mathrm{R}}}^{\text {nom }}
$$

Using (5), (4) can be rewritten as

$$
\begin{aligned}
\cos \mu & \approx-1+\frac{\pi}{2 \sqrt{6} N_{\mathrm{T}_{\mathrm{R}}}} \frac{I_{\mathrm{R}, \mathrm{ac}}}{I_{\mathrm{R}, \mathrm{dc}}} \cos \phi \\
& \approx-1+\frac{\pi}{6 \sqrt{6} N_{\mathrm{T}_{\mathrm{R}}}} \frac{P_{\mathrm{F}}}{U_{\mathrm{F}} I_{\mathrm{dc}}} .
\end{aligned}
$$

Using (8), $\cos \mu$ can be estimated from measurements for different operating points. $\tilde{\mu}$ can then be calculated as

$$
\tilde{\mu}=\arccos (\overline{\cos \mu}),
$$

where $\overline{\cos \mu}$ is the mean of the estimated values for $\cos \mu$.

\section{Wind Turbine Front-End Converter Controls}

The front-end (grid-/line-side) network of the $k$ th wind turbine(s), $\mathrm{WT}_{k}$, is shown in Fig. 1b. The grid-forming WT front-end (grid-/line-side) converter (FEC) controls, shown in Fig. 3, are based on those proposed in [6] and are implemented on a rotating reference frame oriented on the voltage at the filter capacitor, $U_{\mathrm{T}, k}$.

In each WT front-end network, the filter capacitor voltage direct (d) and quadrature (q) axis components are regulated by the FEC lower/inner control loops to follow the corresponding references, $U_{\mathrm{Td}, k}^{*}, U_{\mathrm{Tq}, k}^{*}$, respectively. $U_{\mathrm{Td}, k}^{*}$ consists of two components: the offshore ac network voltage set point, $U_{0}$, common to all WTs, and a component individual to each WT, which is altered to control the FEC active power output, $P_{\mathrm{T}, k}$. In an additional control loop based on the FEC phaselocked loop (PLL), a proportional regulator manipulates $U_{\mathrm{Tq}, k}^{*}$ to control the offshore ac network (angular) frequency, $\omega$. The reference to such additional loop also consists of two components: the offshore ac network (angular) frequency set point, $\omega_{0}$, common to all WTs, and a component individual to each WT, which is altered to control the FEC reactive power output, $Q_{\mathrm{T}, k}$.

When the WF is exporting power, the FEC upper/outer control loops in each WT regulate $P_{\mathrm{T}, k}$ and $Q_{\mathrm{T}, k}$ as follows. A proportional-integral (PI) regulator controls $P_{\mathrm{T}, k}$ to follow the corresponding reference, $P_{\mathrm{T}, k}^{*}$, whereas $Q_{\mathrm{T}, k}$ is controlled by a proportional regulator (reactive-power-frequency droop) with a given reference, $Q_{\mathrm{T}, k}^{*}$, so that reactive power is shared among the WT FECs (avoiding overcurrents and reactive current circulation). Values for the control parameters and limits are given in Table IV.

\section{Wind Farm Active Power Controls}

To study the capability of such a WF to provide FS to an onshore ac network, the model is extended to include the supervisory active power controls at plant level shown in Fig. 4, based on those used in [11], [12], [16]. Values for the parameters and limits are given Table V.

On the right side of Fig. 4, a proportional-integral (PI) regulator controls the WF active power output, $P_{\mathrm{F}}$, by altering the WF active power dispatch, $P^{*}$. A first-order LPF is applied to the corresponding measurement signal. Hardware and control limits are modelled by means of corresponding restrictions on the regulator's output value and its rate of change. Proportional WF generation dispatch is used. In doing so, $P^{*}$ is divided by the overall aerodynamic power available from the wind, $P_{\text {ava }}$, to generate the OWF active power dispatch coefficient, $\kappa_{\text {disp. }}$. The active power set point of each WT FEC is then set as the product of the corresponding aerodynamic power available from the wind, $P_{\text {ava }, k}$, and the active power dispatch coefficient, i.e.

$$
P_{\mathrm{T}, k}^{*}=\kappa_{\mathrm{disp}} P_{\mathrm{ava}, k} .
$$

When providing FS to the onshore ac network, the base active power reference, $P_{\mathrm{F}}^{*}$, is modified by means of an 


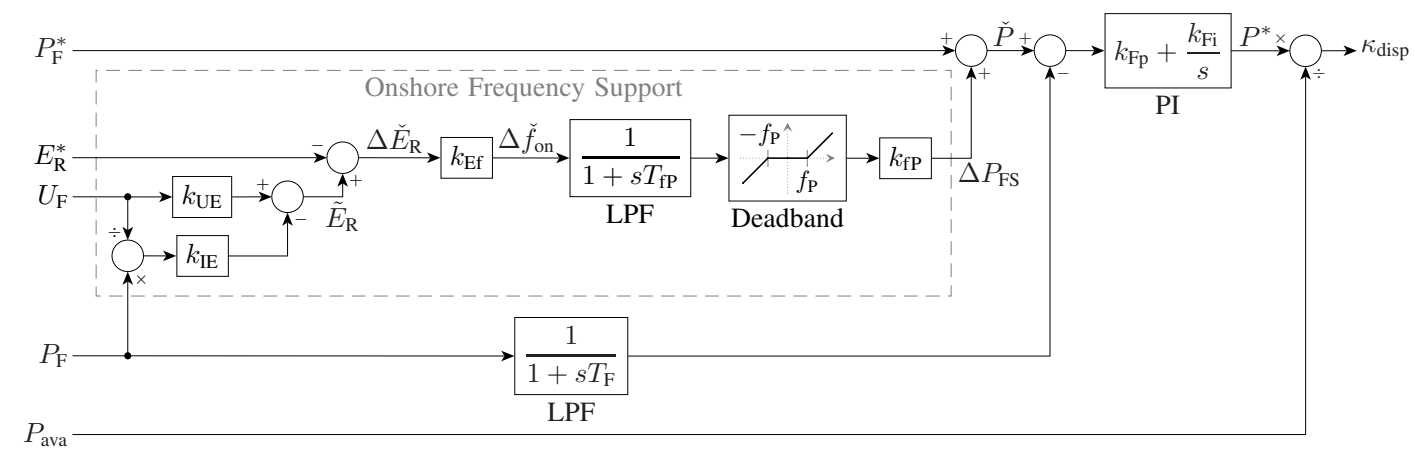

Fig. 4. Wind farm active power controls with Method 1 for providing communication-less frequency support; parameter values and limits given in Table V

additional active power reference, $\Delta P_{\mathrm{FS}}$, based on an onshore frequency deviation signal, $\Delta \check{f}_{\text {on }}$, i.e.

$$
\check{P}=P_{\mathrm{F}}^{*}+\Delta P_{\mathrm{FS}}\left(\Delta \check{f}_{\mathrm{on}}\right) .
$$

PFR is implemented by making $\Delta P_{\mathrm{FS}}$ proportional to $\Delta \check{f}_{\text {on }}$ (to which a first-order LPF and a deadband can also be applied), using a given droop.

When providing CLFS, $\Delta \check{f}_{\text {on }}$ is determined by applying a given droop to the offshore (terminal) direct voltage deviation signal, $\Delta \tilde{E}_{\mathrm{R}}$. Assuming perfect knowledge of the offshore terminal direct voltage, $\Delta \check{E}_{\mathrm{R}} \approx \Delta E_{\mathrm{R}}$,

$$
\Delta \check{f}_{\text {on }}=k_{\mathrm{Ef}} \Delta \check{E}_{\mathrm{R}} \approx k_{\mathrm{Ef}} \Delta E_{\mathrm{R}} .
$$

Equations (2) and (12) can be combined as:

$$
\Delta \check{f}_{\mathrm{on}} \approx k_{\mathrm{Ef}} k_{\mathrm{fE}} \Delta \hat{f}_{\mathrm{on}}=\Delta \hat{f}_{\mathrm{on}} \Longleftrightarrow k_{\mathrm{Ef}} k_{\mathrm{fE}}=1,
$$

which implies that the onshore frequency deviation signal, $\Delta \hat{f}_{\text {on }}$, can be estimated in the WF active power control scheme without any need for long-distance communication. The choice of values for $k_{\mathrm{Ef}}$ and $k_{\mathrm{fE}}$ must ensure that the direct voltage variations due to onshore frequency deviations are sufficiently large to be distinguishable from normal voltage drifts and measurement and estimation uncertainty, but sufficiently small to lie within the allowable operating range. By applying the corresponding deadbands, the controls can ignore small deviations in onshore frequency or offshore terminal direct voltage.

Two different methods are proposed for implementing CLFS in the WF active power controls. In Method $1\left(\mathrm{CLFS}_{1}\right)$, shown in Fig. 4, the estimated offshore terminal direct voltage (6), $\tilde{E}_{\mathrm{R}}$, is used for computing $\Delta \check{E}_{\mathrm{R}}$. In Method $2\left(\mathrm{CLFS}_{2}\right)$, the actual offshore terminal direct voltage measurement, $E_{\mathrm{R}}$, is used instead of $\tilde{E}_{\mathrm{R}}$.

\section{Simulation Results}

Results of the EMT simulations performed in PSCAD are presented in Figs. 5-10. The results illustrated in Figs. 5-8, discussed in Section III-A, correspond to the closed-loop tests conducted to assess the dynamic performance of the proposed CLFS methods and compare it to that of CBFS. Figs. 9 and 10, discussed in Section III-B, correspond to the parametric sensitivity study conducted to asses the proposed CLFS methods' accuracy and sensitivity to parameter estimation errors.
Onshore frequency events have been simulated by means of a $0.075 \mathrm{pu}$ load step change (i.e. $60 \mathrm{MW} / 800 \mathrm{MW}$ ) at $t=0.5 \mathrm{~s}$ for different wind speed scenarios over the whole OWF's operating range. Wind speed (and the aerodynamic power available from it) has been considered constant in each simulation. All (equivalent) WT front-end networks (Fig. 1b) and corresponding grid-forming converter controls (Fig. 3) have the same per-unit (pu) parameters and limits (given in Tables I and IV). Moreover, $U_{0}=0.86 \mathrm{pu}, \omega_{0}=1 \mathrm{pu}$, and $Q_{\mathrm{T}, k}^{*}=0$ in all such controls, and $f_{\mathrm{on}}^{*}=1 \mathrm{pu}=E_{\mathrm{R}}^{*}$ in the controls depicted in Figs. 2 and 4. A maximum allowable variation of $0.06 \mathrm{pu}$ ( $2 \%$ of the HVdc link's rated voltage) has been assumed for $E_{\mathrm{R}}$.

\section{A. Closed-Loop Performance}

Results of the closed-loop tests are shown in Figs. 5-8. Each fig. includes base case responses, corresponding to no FS from the OWF to the onshore ac network (i.e. the FS consisting solely of that of the SM). The (light) grey signals in each fig. represent the base case, while the (dark) red and black traces illustrate the cases in which the OWF provides CBFS and CLFS, respectively. In the case with CBFS, $\Delta \hat{f}_{\text {on }}$ has been assumed to be communicated continuously to the OWF with a delay of $100 \mathrm{~ms}$. Method $1\left(\mathrm{CLFS}_{1}\right)$ has been employed in the case with CLFS. The dynamic performance of the case using $\mathrm{CLFS}_{2}$ is almost identical to that of the case employing $\mathrm{CLFS}_{1}$ and is thus omitted.

High, medium and low wind speed scenarios have been considered in these tests. As with those in [12], the considered individual WT operating points in each scenario take into account the wind speed deficit due to the aerodynamic interaction between WTs. In principle, $P_{\text {ava }, k}$ decreases along the string in the wind speed direction. WF production is curtailed to provide active power reserves of $0.1 \mathrm{pu}$, i.e. $P_{\mathrm{F}}^{*}=P_{\mathrm{ava}}-0.1 \mathrm{pu}$.

WF responses to an onshore underfrequency event at high and low wind speeds are depicted in Figs. 5 and 6, respectively. Similar results have been obtained in the medium wind speed scenario. The offshore ac network (angular) frequency, $\omega$, and WF reactive power output, $Q_{\mathrm{F}}$, are only presented in Fig. 5b, corresponding to the high wind speed scenario. However, similar results have also been obtained in the other wind speed scenarios.

WT responses to an onshore underfrequency event at medium and low wind speeds are illustrated by Figs. 7 and 

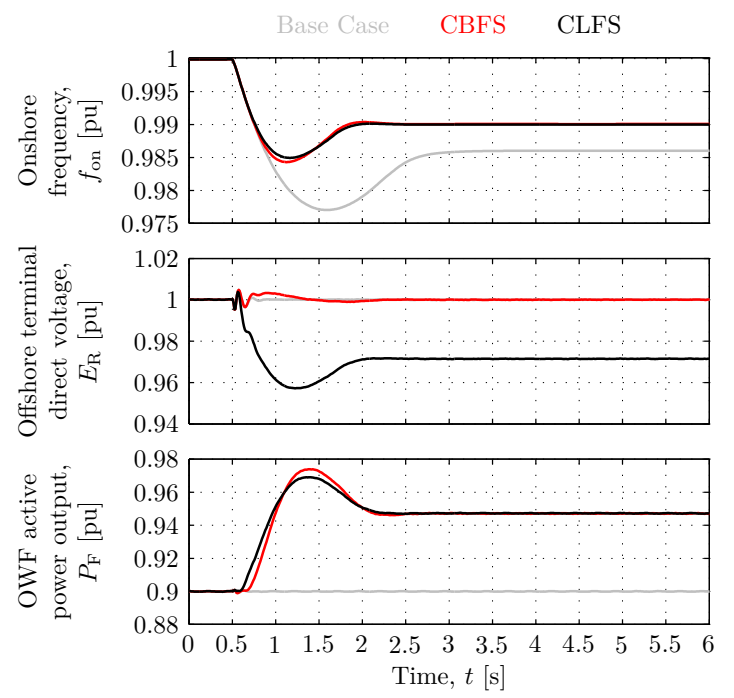

(a)
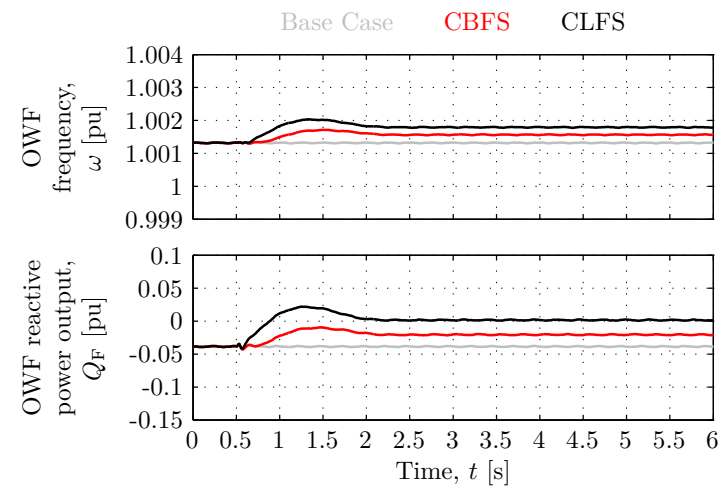

(b)

Fig. 5. Wind farm response to an onshore underfrequency event at high wind speed
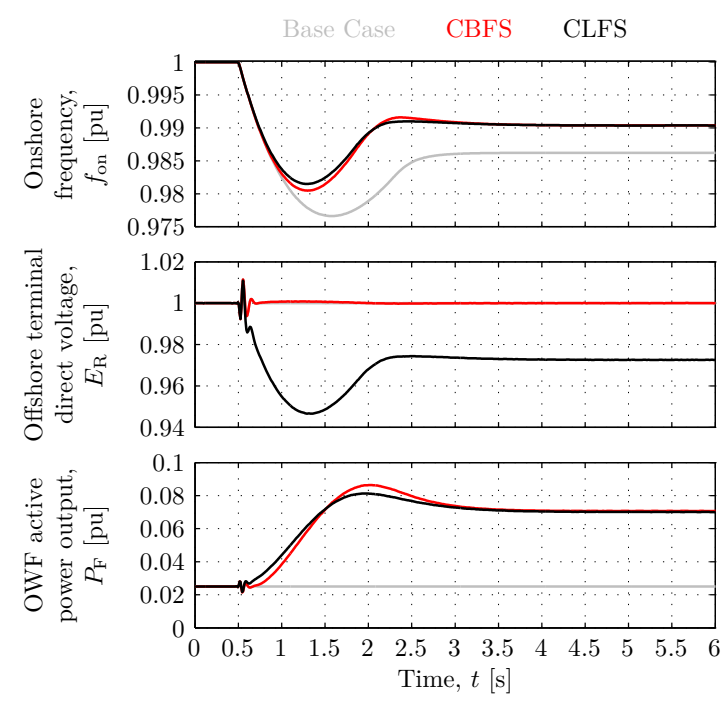

Fig. 6. Wind farm response to an onshore underfrequency event at low wind speed

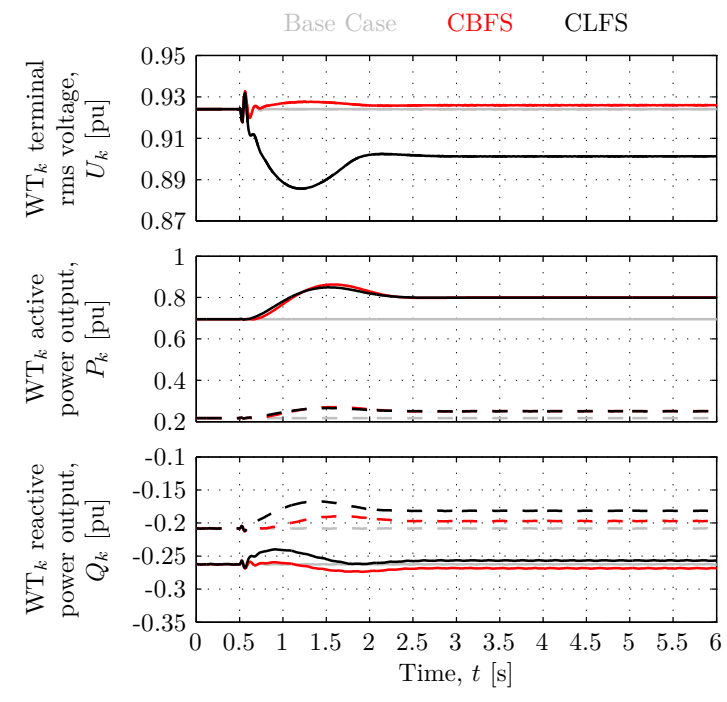

Fig. 7. $k$ th wind turbine response to an onshore underfrequency event at medium-low wind speed - Solid: $k=1$, Dashed: $k=9$

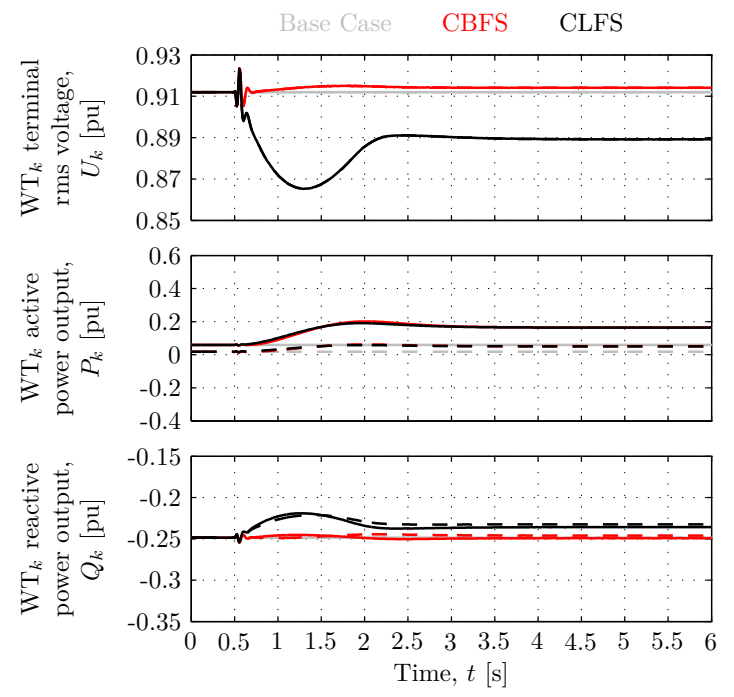

Fig. 8. $k$ th wind turbine response to an onshore underfrequency event at low wind speed - Solid: $k=1$, Dashed: $k=9$

8 , respectively. Solid and dashed traces-superimposed in the case of the WT terminal rms voltages, $U_{k}$-represent the responses of WTs 1 and 9, respectively, corresponding to the turbines at both ends of the string that is represented in detail. Similar results have been obtained in the high wind speed scenario.

The responses in Figs. 5-8 reflect characteristics of DRconnected OWFs observed in literature, such as:

- Active and reactive power flows through the DRs are not decoupled.

- Physical coupling between active power and voltage magnitude in the ac networks of such OWFs arises from the fact that active power flow through the DRs is determined by the voltage difference between their ac and dc terminals.

- As a result, most grid-forming control schemes proposed for WT FECs in DR-connected OWFs manipulate the 
magnitude of the alternating voltage to control the active power flow, and manipulate its frequency to control the reactive power flow.

As can be seen in Figs. 5a and 6 by comparing the base case responses to those of the case with CBFS, the onshore frequency response can be improved by having the OWF provide FS to the onshore ac network. By drawing on the active power reserves and increasing $P_{\mathrm{F}}$, the OWF increases $f_{\text {on }}$ and maintains it at a higher value for as long as the wind allows. The increase in current results in an increase in the DR reactive power consumption. This is reflected in the increases in $Q_{\mathrm{F}}$ and $\omega$ in Fig. 5b. However, such changes are one and three orders of magnitude smaller than that in $P_{\mathrm{F}}$, respectively, while $\omega$ is kept close to $1 \mathrm{pu}$. That is the result of every grid-forming WT FEC contributing autonomously to controlling $\omega$ by means of its corresponding PLL-based proportional regulator, while sharing the reactive power with the other grid-forming WT FECs by means of its reactivepower-frequency droop (proportional regulator) with constant reference $Q_{\mathrm{T}, k}^{*}=0$.

The WT active power outputs, $P_{k}$, in Figs. 7 and 8 reflect the assumed distributions of $P_{\mathrm{ava}, k}$ and the changes in $P^{*}$ and $\kappa_{\text {disp }}$ when FS is provided. In all wind speed scenarios, the increase in $P_{\mathrm{F}}$ in response to the onshore underfrequency event is achieved by an increase in $U_{k}$ that is one order of magnitude smaller, keeping them within their normal operating range, as depicted in both figs. As shown also in both figs., the WTs share the reactive power consumption (negative values of $Q_{k}$ ) according to their power rating and their active power output, $P_{k}$.

The overall performance of the case with CLFS is very similar to that of the case with CBFS, as evidenced by the traces of $f_{\mathrm{on}}$ and $P_{\mathrm{F}}$ in Figs. 5a and 6. A similar amount of energy is injected in both cases, but it is injected at different rates. The dynamic performance of the case with CLFS is slightly better immediately after the event, as the onshore terminal extracts active power from the HVdc link to lower its voltage, and slightly worse after the frequency nadir, as some of the OWF active power output is used to raise such voltage. Such behaviour is, in general, preferable, as the faster response immediately after the event assists in limiting the nadir, while the slower response occurs after the most critical stage of the event has passed.

For similar values of $P_{k}$, the decrease in $U_{k}$ when providing CLFS results in currents higher than those when providing CBFS, as evidenced by the greater values of $Q_{k}$ in Figs. 7 and 8. Higher currents result in increased DR reactive power consumption, which is reflected in the higher values of $\omega$ and $Q_{\mathrm{F}}$ in Fig. 5b for the case with CLFS. The slightly worse static performance (i.e. smaller steady-state values of $f_{\text {on }}$ and $P_{\mathrm{F}}$ in Figs. 5a and 6) can be attributed mainly to the error in the estimation of $E_{\mathrm{R}}$.

Unique features of the provision of CLFS from OWFs connected to $\mathrm{HVdc}$ via DRs are illustrated by the traces of $\omega$ and $U_{\mathrm{k}}$ in Figs. 5b, 7 and 8:

- Since the DRs clamp the magnitude of the alternating voltage in the offshore ac network to the offshore terminal direct voltage, changes in the latter are naturally reflected

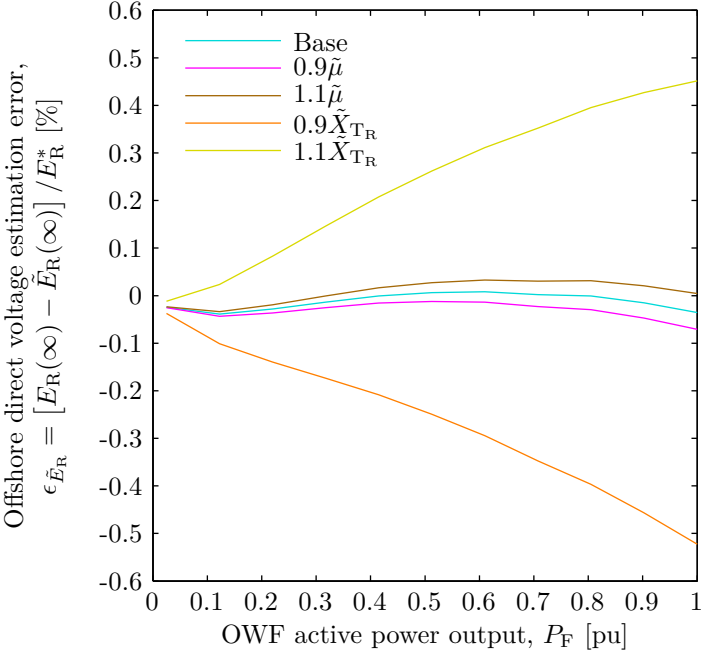

Fig. 9. Parametric sensitivity analysis of the offshore direct voltage estimation

in the former, without the need of an additional control loop.

- The onshore frequency is not mirrored in the offshore ac network, but its deviation is reflected in the magnitude of the alternating voltage in the offshore ac network.

- The OWF active power controls can use the magnitude of the alternating voltage in the offshore ac networkinstead of its frequency - to estimate the active power imbalance in the onshore ac network.

- Since the voltage drop over the DRs varies with the operating point, an accurate provision of CLFS over the whole operating range of the OWF requires knowledge of either the offshore terminal direct voltage or the OWF operating point (e.g. OWF active power or current output).

As illustrated by Fig. 5, the consumption/production of reactive power, necessary to control the offshore ac network (angular) frequency, $\omega$, can reduce the active power headroom of the corresponding grid-forming WTs. Lowering the voltage in response to an onshore underfrequency event may thus require a greater WT FEC current headroom to provide the necessary additional active power at high wind speeds. Moreover, there is a trade-off at low wind speeds between the maximum allowable variation of $E_{\mathrm{R}}$ and the minimum allowable WT terminal rms voltage, $U_{k}$, as can be observed in Fig. 8. For example, increasing the variation of $E_{\mathrm{R}}$ may result in values of $U_{k}$ below $0.85 \mathrm{pu}$.

\section{B. Accuracy and Sensitivity to Parameter Estimation Errors}

To assess the impact of parameter estimation errors (i.e. in the estimation of $\tilde{R}_{\mathrm{dc}}$ in both methods, plus $\tilde{\mu}$ and $\tilde{X}_{\mathrm{T}_{\mathrm{R}}}$ in $\mathrm{CLFS}_{1}$ ) on the provision of CLFS, a parametric sensitivity study has been performed, with the results shown in Figs. 9 and 10. The study has consisted of open-loop tests, in which the onshore terminal modulates the HVdc link voltage in proportion to the onshore frequency deviation (1), but the OWF does not provide FS to the onshore ac network, i.e. the OWF active power output, $P_{\mathrm{F}}$, remains constant. The same 


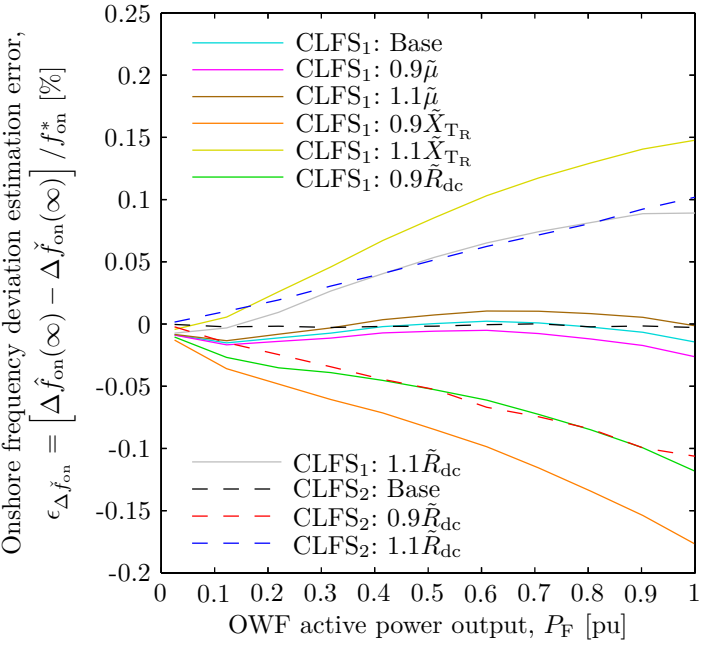

Fig. 10. Parametric sensitivity analysis of the onshore frequency deviation estimation

aerodynamic power available from the wind has been considered for all WTs. Moreover, no active power reserves from preventively curtailed OWF production have been considered, i.e. $P_{\mathrm{F}}^{*}=P_{\mathrm{ava}}$.

The plots represent the steady-state values of different quantities from the dynamic simulations of onshore underfrequency events similar to those in Section III-A, for different operating points (i.e. OWF active power output, $P_{\mathrm{F}}$ ) in the OWF operating range. Moreover, they include base cases, corresponding to $\tilde{R}_{\mathrm{dc}} \approx R_{\mathrm{dc}}$ and the recommended estimation of $\tilde{X}_{\mathrm{T}}$ and $\tilde{\mu}$, (7), (9). The corresponding values are given in Tables II and III. The onshore underfrequency events have been arranged so that the steady-state value of the onshore frequency deviation signal, $\Delta \hat{f}_{\text {on }}(\infty)$, has a magnitude of about $0.0136 \mathrm{pu}$ (e.g. $0.68 \mathrm{~Hz}$ for $f_{\mathrm{on}}^{*}=50 \mathrm{~Hz}$ ) in every simulation. However, similar results can be expected over the assumed ranges for onshore frequency deviation signal and offshore direct voltage, $\Delta \hat{f}_{\text {on }} \in[-0.02,0.02] \mathrm{pu} \quad, \quad E_{\mathrm{R}} \in[0.94,1.06] \mathrm{pu}$.

Fig. 9 illustrates the accuracy of the offshore terminal direct voltage estimation (6), $\tilde{E}_{\mathrm{R}}$, used in $\mathrm{CLFS}_{1}$, and its sensitivity to errors in the estimation of $\tilde{X}_{T_{\mathrm{R}}}$ and $\tilde{\mu}$. This is done by representing the error of $\tilde{E}_{\mathrm{R}}, \epsilon_{\tilde{E}_{\mathrm{R}}}=\left(E_{\mathrm{R}}-\tilde{E}_{\mathrm{R}}\right) / E_{\mathrm{R}}^{*}$, for the base case parameter values and variations of $\pm 10 \%$. Variations in $\tilde{R}_{\mathrm{dc}}$ have a negligible effect on $\epsilon_{\tilde{E}_{\mathrm{R}}}$ (i.e. they are reflected in both terms of the subtraction) and are thus omitted.

Fig. 10 depicts the accuracy of the onshore frequency deviation estimation (12), $\Delta \check{f}_{\text {on }}$, and its sensitivity to errors in the estimation of $\tilde{R}_{\mathrm{dc}}, \tilde{X}_{\mathrm{T}_{\mathrm{R}}}$ and $\tilde{\mu}$ for both CLFS methods. This is done by representing the error of $\Delta \check{f}_{\text {on }}, \epsilon_{\Delta \check{f}_{\text {on }}}=$ $\left(\Delta \hat{f}_{\text {on }}-\Delta \check{f}_{\text {on }}\right) / f_{\text {on }}^{*}$, for the base case parameter values and for variations of $\pm 10 \%$. The solid traces represent the cases with $\mathrm{CLFS}_{1}$, while the dashed traces correspond to the cases with CLFS ${ }_{2}$. Variations in $\tilde{X}_{\mathrm{T}_{\mathrm{R}}}$ and $\tilde{\mu}$ are only relevant to $\mathrm{CLFS}_{1}$ and are thus omitted for $\mathrm{CLFS}_{2}$.

As evidenced by the cyan (base case) trace in Fig. 9, the results indicate that the proposed method (6) for estimating $E_{\mathrm{R}}$ can be expected to have an error, $\epsilon_{\tilde{E}_{\mathrm{R}}}$, of around $0.03 \%$ in magnitude (i.e. $64 \mathrm{~V}$ for $E_{\mathrm{R}}^{*} \approx 213 \mathrm{kV}$ ), which may be inherent to any estimation of $E_{\mathrm{R}}$. As a consequence, $\epsilon_{\Delta \check{f}_{\mathrm{on}}}$ can be expected to be around 0.01 percentage points (e.g. $5 \mathrm{mHz}$ for $f_{\mathrm{on}}^{*}=50 \mathrm{~Hz}$ ) greater when using $\mathrm{CLFS}_{1}$, as illustrated by the cyan and black (base case) curves in Fig. 10. Variations in $\tilde{R}_{\mathrm{dc}}, \tilde{X}_{\mathrm{T}_{\mathrm{R}}}$ and $\tilde{\mu}$ impact the estimations of offshore direct voltage and onshore frequency deviation in a manner that is directly proportional to $P_{\mathrm{F}}$, as can be seen in both figs. This reflects the role of such parameters in the estimation of the corresponding voltage drops in the DR platform and $\mathrm{HVdc}$ link, which are directly proportional to $P_{\mathrm{F}}$. The maximum values of $\epsilon_{\tilde{E}_{\mathrm{R}}}$ and $\epsilon_{\Delta \breve{f}_{\mathrm{on}}}$ thus correspond to $P_{\mathrm{F}}=1 \mathrm{pu}$.

When using CLFS ${ }_{1}$, an error of $\pm 10 \%$ in the estimation of $\tilde{\mu}$ can result in greater magnitudes of $\epsilon_{\tilde{E}_{\mathrm{R}}}$ and $\epsilon_{\Delta \tilde{f}_{\mathrm{on}}}$, as depicted by the magenta and brown traces in Figs. 9 and 10 , respectively. Such magnitudes can be as high as $0.06 \%$ and $0.02 \%$, respectively. Likewise, an error of $\pm 10 \%$ in the estimation of $\tilde{X}_{\mathrm{T}_{\mathrm{R}}}$ can result in magnitudes of $\epsilon_{\tilde{E}_{\mathrm{R}}}$ and $\epsilon_{\Delta \check{f}_{\mathrm{on}}}$ as high as $0.52 \%$ and $0.17 \%$, respectively, as illustrated by the orange and yellow curves in Figs. 9 and 10, respectively.

An error of $\pm 10 \%$ in the estimation of $\tilde{R}_{\mathrm{dc}}$ can result in magnitudes of $\epsilon_{\Delta \check{f}_{\mathrm{on}}}$ as high as $0.12 \%$, which indicates that $\epsilon_{\Delta \breve{f}_{\mathrm{on}}}$ is more sensitive to errors in the estimation of $\tilde{R}_{d c}$ than to errors in the estimation of $\tilde{\mu}$, but is even more sensitive to errors in the estimation of $\tilde{X}_{\mathrm{T}_{\mathrm{R}}}$. As illustrated by the red and blue curves, the $\pm 10 \%$ error in the estimation of $\tilde{R}_{\mathrm{dc}}$ has a similar effect on $\epsilon_{\Delta \breve{f}_{\text {on }}}$ when using $\mathrm{CLFS}_{2}$. Moreover, similar accuracy and sensitivity to errors in the estimation of $\tilde{R}_{\mathrm{dc}}$ can be expected when VSC-connected OWFs provide CLFS.

In OWFs, transformers are typically purpose-built, meaning that the uncertainty in the estimation of $\tilde{X}_{\mathrm{T}_{\mathrm{R}}}$ can be reduced significantly by measuring their impedance during acceptance tests. The uncertainty in the estimation of $\tilde{R}_{\mathrm{dc}}$ can be reduced by the distributed temperature sensing systems typically employed in large OWFs. Since the corresponding thermal time constants are much greater, corrections in $\tilde{R}_{\mathrm{dc}}$ can be done at a lower frequency, e.g. every 10 minutes. Moreover, adaptive estimators can also be used to correct the values of $\tilde{\mu}, \tilde{X}_{\mathrm{T}_{\mathrm{R}}}$ and $\tilde{R}_{\mathrm{dc}}$ at similar frequencies.

\section{Conclusions}

The simulation results indicate that the new connection concept using DRs (and corresponding changes in WT control) does not impact the capability of OWFs to provide CLFS by means of plant-level active power control strategies similar to those developed for OWFs connected to HVdc via VSCs. The onshore frequency is not mirrored in the offshore ac network, but its deviation is reflected in the magnitude of the alternating voltage in the offshore ac network, while the offshore frequency varies relatively little. The proposed OWF active power controls can use the magnitude of the alternating voltage in the offshore ac network-instead of its frequencyto estimate the active power imbalance in the onshore ac network. In this way, DR-connected OWFs respond to onshore frequency events, while their grid-forming WTs share the reactive power consumption/production and keep the offshore frequency and voltages within their normal operating ranges.

The overall performance of the case with CLFS is similar to that of the case with CBFS. The dynamic performance 
is slightly better immediately after the event, as the onshore terminal extracts active power from the HVdc link to lower its voltage, and slightly worse after the frequency nadir, as some of the OWF active power output is used to raise such voltage. Such behaviour is, in general, preferable, as the faster response immediately after the event assists in limiting the nadir, while the slower response occurs after the most critical stage of the event has passed.

\section{APPENDIX}

TABLE I

PARAMETERS OF THE STUDIED SYSTEM

\begin{tabular}{|c|c|c|}
\hline Component & Parameter(s) & Value(s) \\
\hline $\begin{array}{c}\text { HVdc } \\
\text { link }\end{array}$ & $\begin{array}{l}\text { Rated power } \\
\text { Rated pole-to-ground voltage } \\
\text { Nominal power } \\
\text { Nominal pole-to-pole voltage }\end{array}$ & $\begin{array}{l}1200 \mathrm{MW} \\
\pm 320 \mathrm{kV} \\
400 \mathrm{MW} \\
213 \mathrm{kV}\end{array}$ \\
\hline $\begin{array}{c}\text { Synchronous } \\
\text { machine } \\
+ \\
\text { turbine } \\
+ \\
\text { governor }\end{array}$ & $\begin{array}{c}\text { Rated apparent power } \\
\text { Rated rms line-to-line voltage } \\
\text { Inertia time constant } \\
\text { Water starting time } \\
\text { Penstock head loss coefficient } \\
\text { Turbine damping constant } \\
\text { Governor permanent droop } \\
\text { Governor proportional gain } \\
\text { Governor integral gain } \\
\text { Governor derivative gain } \\
\text { Pilot servomotor time constant } \\
\text { Gate servo(motor) time constants }\end{array}$ & $\begin{array}{c}400 \mathrm{MVA} \\
133 \mathrm{kV} \\
1.5 \mathrm{~s} \\
0.01 \mathrm{~s} \\
0.1 \mathrm{pu} \\
3 \mathrm{pu} \\
1 \times 10^{-3} \mathrm{pu} \\
10 \mathrm{pu} \\
0 \\
0 \\
0.01 \mathrm{~s} \\
0\end{array}$ \\
\hline $\begin{array}{l}\text { Onshore } \\
\text { HVdc } \\
\text { terminal }\end{array}$ & $\begin{array}{c}\text { Equivalent capacitance } \\
\text { Arm inductance } \\
\text { Arm resistance }\end{array}$ & $\begin{array}{c}131 \mu \mathrm{F} \\
206 \mathrm{mH} / \text { phase } \\
586 \mathrm{~m} \Omega / \text { phase }\end{array}$ \\
\hline $\begin{array}{l}\text { Diode } \\
\text { rectifier } \\
\text { platform }\end{array}$ & $\begin{array}{l}\text { DR transformer }(\mathrm{Y} / \mathrm{Y} / \Delta) \text { rated } \\
\text { rms line-to-line voltages } \\
\text { DR transformer leakage reactance, } X_{\mathrm{T}_{\mathrm{R}}}^{\text {nom }} \\
\text { Equivalent dc smoothing reactor } \\
\text { Shunt compensation inductance }\end{array}$ & $\begin{array}{c}66 / 43.4 / 43.4 \mathrm{kV} \\
1.41 \Omega / \text { phase } \\
33.3 \mathrm{H} / \text { pole } \\
1.77 \mathrm{H} / \text { phase }\end{array}$ \\
\hline $\begin{array}{l}\text { Wind } \\
\text { turbine } \\
\text { (front-end } \\
\text { network) }\end{array}$ & $\begin{array}{c}\text { Rated apparent power } \\
\text { Transformer }(\mathrm{Y} / \Delta) \text { rated } \\
\text { rms line-to-line voltages } \\
\text { Transformer leakage inductance } \\
\text { Transformer resistance } \\
\text { Filter capacitance, } C_{k} \\
\text { Filter inductance, } L_{k} \\
\text { Filter resistance, } R_{k}\end{array}$ & $\begin{array}{c}8 \mathrm{MVA} \\
0.69 / 66 \mathrm{kV} \\
0.1 \mathrm{pu} / \mathrm{ph} \text { ase } \\
0.01 \mathrm{pu} / \mathrm{ph} \text { ase } \\
0.05 \mathrm{pu} / \mathrm{ph} \text { ase } \\
0.1 \mathrm{pu} / \mathrm{ph} \text { ase } \\
0\end{array}$ \\
\hline
\end{tabular}

TABLE II

ONSHORE TERMINAL OUTER CONTROL LOOP PARAMETERS AND LIMITS

\begin{tabular}{cccc}
\hline Par. & Value & Par. & Value \\
\hline$f_{\mathrm{E}}$ & $5 \times 10^{-4} \mathrm{pu}$ & $\tilde{R}_{\mathrm{dc}}$ & $3.05 \times 10^{-2} \mathrm{pu}$ \\
$k_{\mathrm{fE}}$ & $3 \mathrm{pu}$ & $T_{\mathrm{fE}}$ & $10 \mathrm{~ms}$ \\
\hline Limits: & \multicolumn{3}{c}{$-0.06 \mathrm{pu} \leq \Delta \hat{E} \leq 0.06 \mathrm{pu}$} \\
\hline
\end{tabular}

TABLE III

OFFSHORE TERMINAL DIRECT VOLTAGE ESTIMATION PARAMETERS

\begin{tabular}{cccccc}
\hline Par. & Value & Par. & Value & Par. & Value \\
\hline$\tilde{\mu}$ & $22.3^{\circ}$ & $N_{\mathrm{T}_{\mathrm{R}}}$ & $43.37 / 66$ & $\tilde{X}_{\mathrm{T}_{\mathrm{R}}}$ & $1.41 \Omega /$ phase \\
\hline
\end{tabular}

TABLE IV

$k$ TH WIND TURBINE FRONT-END (GRID-/LINE-SIDE) CONVERTER CONTROL PARAMETERS AND LIMITS

\begin{tabular}{cccccc}
\hline Par. & Value & Par. & Value & Par. & Value \\
\hline$\tilde{C}_{k}$ & $0.05 \mathrm{pu}$ & $k_{\mathrm{Lp}, k}$ & $0.16 \mathrm{pu}$ & $k_{\mathrm{Q}, k}$ & $0.01 \mathrm{pu}$ \\
$k_{\mathrm{Ii}, k}$ & $0.04 \mathrm{pu} / \mathrm{s}$ & $k_{\omega, k}$ & $50 \mathrm{pu}$ & $k_{\mathrm{Ui}, k}$ & $40 \mathrm{pu} / \mathrm{s}$ \\
$k_{\mathrm{Ip}, k}$ & $0.4 \mathrm{pu}$ & $k_{\mathrm{Pi}, k}$ & $40 \mathrm{pu} / \mathrm{s}$ & $k_{\mathrm{Up}, k}$ & $4 \mathrm{pu}$ \\
$k_{\mathrm{Li}, k}$ & $1.6 \times 10^{-4} \mathrm{pu} / \mathrm{s}$ & $k_{\mathrm{Pp}, k}$ & $4 \mathrm{pu}$ & $\tilde{L}_{k}$ & $0.1 \mathrm{pu}$ \\
\hline Limits: & $0 \leq I_{\mathrm{T}, k}^{*} \leq 1.1 \mathrm{pu}$ & $0 \leq U_{\mathrm{W}, k}^{*} \leq 1.1 \mathrm{pu}$ \\
\hline
\end{tabular}

TABLE V

WIND FARM ACTIVE POWER CONTROL PARAMETERS AND LIMITS

\begin{tabular}{cccccc}
\hline Par. & Value & Par. & Value & Par. & Value \\
\hline$f_{\mathrm{P}}$ & 0 & $k_{\mathrm{Fp}}$ & $1 \times 10^{-3} \mathrm{pu}$ & $k_{\mathrm{UE}}$ & $1.10 \mathrm{pu}$ \\
$k_{\mathrm{Ef}}$ & $0.333 \mathrm{pu}$ & $k_{\mathrm{Fi}}$ & $5 \mathrm{pu} / \mathrm{s}$ & $T_{\mathrm{F}}$ & $10 \mathrm{~ms}$ \\
$k_{\mathrm{fP}}$ & $-5 \mathrm{pu}$ & $k_{\mathrm{IE}}$ & $4.48 \times 10^{-2} \mathrm{pu}$ & $T_{\mathrm{fP}}$ & $10 \mathrm{~ms}$ \\
\hline \multicolumn{6}{c}{$1 \times 10^{-3} \mathrm{pu} \leq U_{\mathrm{F}}, 1 \times 10^{-3} \mathrm{pu} \leq P_{\mathrm{ava}}}$, \\
Limits: & \multicolumn{5}{c}{$-0.1 \mathrm{pu} \leq \Delta P_{\mathrm{FS}} \leq 0.1 \mathrm{pu}}$, \\
& $0.025 \mathrm{pu} \leq P^{*} \leq 1.1 \mathrm{pu},-1 \mathrm{pu} / \mathrm{s} \leq \mathrm{d} P^{*} / \mathrm{d} t \leq 1 \mathrm{pu} / \mathrm{s}$ \\
\hline
\end{tabular}

\section{ACKNOWLEDGEMENT}

The authors gratefully acknowledge the contributions of Poul E. Sørensen to the discussions leading up to this work.

\section{REFERENCES}

[1] R. M. Blasco-Giménez, S. C. Añó-Villalba, J. Rodríguez-D’Derlée, F. Morant-Anglada, and S. I. Bernal-Pérez, "Distributed Voltage and Frequency Control of Offshore Wind Farms Connected With a DiodeBased HVdc Link," IEEE Transactions on Power Electronics, vol. 25, no. 12, pp. 3095-3105, Dec. 2010.

[2] R. M. Blasco-Giménez, S. C. Añó-Villalba, J. Rodríguez-D’Derlée, S. I. Bernal-Pérez, and F. Morant-Anglada, "Diode-Based HVdc Link for the Connection of Large Offshore Wind Farms," IEEE Transactions on Energy Conversion, vol. 26, no. 2, pp. 615-626, Mar. 2011.

[3] S. I. Bernal-Pérez, S. C. Añó-Villalba, R. M. Blasco-Giménez, and J. Rodríguez-D'Derlée, "Efficiency and Fault Ride-Through Performance of a Diode-Rectifier- and VSC-Inverter-Based HVDC Link for Offshore Wind Farms," IEEE Transactions on Industrial Electronics, vol. 60, no. 6, pp. 2401-2409, Jun. 2013.

[4] T. Christ, S. Seman, and R. Zurowski, "Investigation of DC Converter Nonlinear Interaction with Offshore Wind Power Park System," in Proceedings of the 2015 EWEA Offshore Conference, Copenhagen, Denmark, Mar. 10-12, 2015.

[5] P. Menke, R. Zurowski, T. Christ, S. Seman, G. Giering, T. Hammer, W. Zink, F. Hacker, D. Imamovic, J. Thisted, P. Brogan, and N. Goldenbaum, "2nd Generation DC Grid Access for Large Scale Offshore Wind Farms," in Proceedings of the 14th Wind Integration Workshop, Brussels, Belgium, Oct. 20-22, 2015.

[6] L. Yu, R. Li, and L. Xu, "Distributed PLL-Based Control of Offshore Wind Turbines Connected With Diode-Rectifier-Based HVDC Systems," IEEE Transactions on Power Delivery, vol. 33, no. 3, pp. 1328-1336, Jun. 2018.

[7] PROMOTioN, "Deliverable 3.1: Detailed functional requirements to WPPs," Project Deliverable, Dec. 2016. [Online]. Available: https:// www. promotion - offshore. net/fileadmin/PDFs/D3.1_PROMOTioN Deliverable_3.1_Detailed_functional_requirements_to_WPPs.pdf.

[8] L. Fan, Z. Miao, and D. Osborn, "Wind Farms With HVDC Delivery in Load Frequency Control," IEEE Transactions on Power Systems, vol. 24 no. 4, pp. 1894-1895, Nov. 2009.

[9] Y. Pipelzadeh, B. Chaudhuri, and T. C. Green, "Inertial Response from Remote Offshore Wind Farms Connected Through VSC-HVDC Links: A Communication-less Scheme," in Proceedings of the IEEE PES 2012 General Meeting, San Diego, CA, United States, Jul. 22-26, 2012. 
[10] Y. Phulpin, "Communication-Free Inertia and Frequency Control for Wind Generators Connected by an HVDC-Link," IEEE Transactions on Power Systems, vol. 27, no. 2, pp. 1136-1137, May 2012.

[11] PROMOTioN, "Deliverable 3.5: Performance of ancillary services provision from WFs connected to DR-HVDC," Project Deliverable, Jan. 2018. [Online]. Available: https://www. promotion - offshore.net/fileadmin/ PDFs/D3.5_PROMOTioN_Performance_of_ancillary_services_provision_from_WFs_connected_to_DR-HVDC.pdf.

[12] O. Saborío-Romano, A. Bidadfar, J. N. Sakamuri, Ö. Göksu, and N. A. Cutululis, "Primary Frequency Response from Offshore Wind Farms Connected to HVdc via Diode Rectifiers," in Proceedings of the 13th IEEE PES PowerTech Conference, Milan, Italy, Jun. 23-27, 2019.

[13] PROMOTioN, "Deliverable 3.2: Specifications of the control strategies and the simulation test cases," Project Deliverable, Mar. 2017. [Online]. Available: https://www.promotion-offshore.net/fileadmin/PDFs/D3.2_ Specifications_Control_strategies_and_simulation_test_cases.pdf.

[14] L. Xie, L. Yao, Y. Li, L. Xu, Z. Wang, C. Wei, and C. Fan, "Frequency regulation participation of offshore wind farm integrated by diode-rectifer HVDC system," The Journal of Engineering, vol. 2019, pp. 977-981, 16 Apr. 2019.

[15] E. Muljadi, S. Pasupulati, A. Ellis, and D. Kosterov, "Method of Equivalencing for a Large Wind Power Plant with Multiple Turbine Representation," in Proceedings of the IEEE PES 2008 General Meeting, Pittsburgh, PA, United States, Jul. 20-24, 2008.

[16] L. Zeni, "Power system integration of VSC-HVDC connected wind power plants: Control principles, power system services, clustering of wind power plants," Ph.D. dissertation, Technical University of Denmark, Roskilde, Denmark, Mar. 2015.

[17] P. Kundur, Power System Stability and Control. New York, NY, United States: McGraw-Hill, 1994.

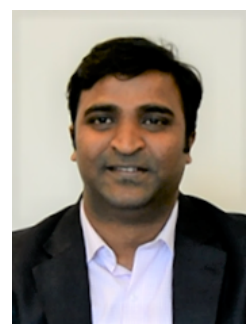

Jayachandra N. Sakamuri received the MTech degree in Electrical Engineering from the Indian Institute of Technology in 2009, after spending a year as an exchange student at the Technical University of Berlin in 2008. He obtained his PhD degree from the Department of Wind Energy at the Technical University of Denmark, where his work focused on coordinated control of wind farms in offshore HVdc grids. Before the $\mathrm{PhD}$, he worked for Grid System R\&D, ABB on HVdc System Design for three years and also at Crompton Greaves Ltd. on HV switchgear design. His research interests include HVdc, offshore wind farm integration and control, and HV switchgear design.

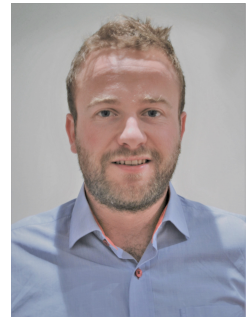

Lorenzo Zeni (S'13-M'16) is with Ørsted Offshore, Denmark. He holds BSc and MSc degrees in Electrical Engineering from the University of Padua, as well as a MSc degree in Sustainable Energy from the Technical University of Denmark. He conducted an industrially-driven $\mathrm{PhD}$ study on HVdc connection of wind farms with the Technical University of Denmark and DONG Energy (now Ørsted). He is involved in electrical design and grid connection activities for offshore wind farms as well as $R \& D$ and $\mathrm{HVdc}$ to offshore wind farms.

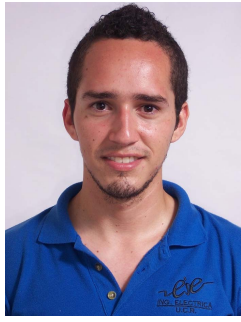

Oscar Saborío-Romano (S'12) received the BSc (Hons) degree in Electrical Engineering from the University of Costa Rica in 2013. In 2015, he received the MSc degrees in Electrical Engineering and Wind Energy from Delft University of Technology and the Norwegian University of Science and Technology, respectively. He joined the Department of Wind Energy at the Technical University of Denmark in 2016, where he has pursued a PhD. His research interests include power system control and stability, integration of renewable energy sources, modelling and control of wind power, HVdc transmission, and microgrids.

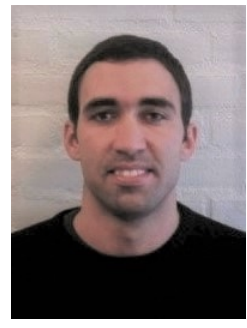

Ömer Göksu received the BSc and MSc degrees in Electrical and Electronics Engineering from the Middle East Technical University in 2004 and 2008, respectively, and was employed in Aselsan Inc. from 2004 to 2009. He obtained his PhD degree from the Department of Energy Technology at Aalborg University in 2012, under the Vestas Power Programme. In 2013, he was a research associate at the University of Manchester. Since 2013 he is a researcher at the Department of Wind Energy, Technical University of Denmark. His research is focused on ac and HVdc connected wind turbine and wind farm control and modelling, and integration of power electronics to power systems.

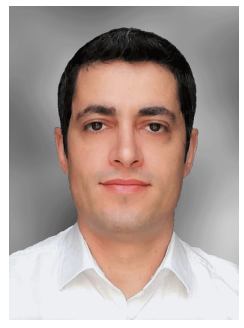

Ali Bidadfar (M'14) worked as a power system researcher at KTH Royal Institute of Technology from 2013 to 2016. He has been a $\mathrm{PhD}$ researcher at the Technical University of Denmark since 2016. During his $\mathrm{PhD}$, he has focused on frequency support provision from offshore HVdc grids. In August 2019, he joined Ørsted, Denmark, as a power system engineer. His research interests include $\mathrm{HVdc}$ control and operation, offshore wind generation and transmission technologies, control and stability of power systems.

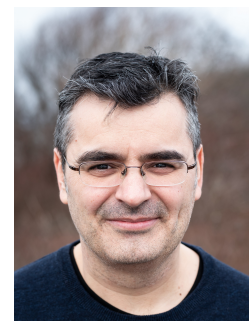

Nicolaos A. Cutululis (SM'18) received the MSc and $\mathrm{PhD}$ degrees, both in Automatic Control, in 1998 and 2005, respectively. Currently, he is a professor at the Department of Wind Energy, Technical University of Denmark. His main research interests are integration of wind power, with a special focus on offshore wind power, and grids. 